\title{
Reasons for delay in undescended testis: the results of two pediatric surgery centers
}

\author{
Erdal Türk, Fahri Karaca, Yeşim Edirne, Cem Mehmet Bilen \\ Denizli State Hospital Pediatric Surgery Clinics, Denizli, Turkey
}

\section{Summary}

Aim: We evaluated the age at surgery, family educational level and the physician's roles in cases of undescended testis operated in our clinic of age. Material and Method: A total of 463 patients operated for undescended testis were divided into two groups as older and younger than two years. An interview was conducted with 90 families from each group to query the family education level, how the diagnosis was made and by whom the diagnosis was made including the reasons for delay in the diagnosis, if any.

Results: A total of 494 testes of 463 patients examined at the Pediatric Surgery Clinics of Denizli State Hospital and Ordu Obstetric and Pediatric Hospital between 2006 and 2011 were included in the study. The percentages of the patients older and younger than two years were $59.4 \%$ ( $n=275$ patients, Group 1) and 40.6\% ( $n=188$ patients, Group 2), respectively. The parents were graduates of primary school in $67.2 \%$ of the cases and graduates of high school or university in $20 \%$ of the cases in the first group, while the respective percentages were $38.8 \%$ and $41.6 \%$ in the second group $(p<0.05)$. In the first group, the parents stated that they were not aware of the problem in $86.6 \%$ of the cases, while it was stated that the child had been examined by other physicians for other reasons previously in $97.7 \%$ of the cases.

Conclusions: An important reason for delay in diagnosis of undescended testis in our country may be due to low educational levels of families and the negligence of the physicians regarding the genital examination. (Turk Arch Ped 2013; 48: 44-47)

Key words: Undescended testis, orchiopexy, parents

\section{Introduction}

It has been reported that the risk of development of malign degeneration in cases of undescended testis is 3-10 fold higher compared to the normal population, but bringing the testicle into the scrotum does not decrease this risk, but can stop the process of degeneration (1). Although more scientific evidence is needed, the main discussion is preserving the testicular germ cell maturation (2). The genocyte of the newborn is transformed into a type A spermatogonium at the age of 3-12 months as stimulated by the process called "minipuberty". It is thought that this step is necessary for fertility later, because the stem cells for spermatogenesis are produced by this structure. This step can be affected in undescended testis. To avoid this and to provide normal maturation orchiopexy is performed at the age of 6-12 months in many centers currently $(2,3)$.

In this study, the relation between the family's level of education and the age at the time of surgery and the role and attention physicians in diagnosis were investigated in children with undescended testis operated both at the appropriate age and in the late period.

\section{Material and Method}

463 patients who were operated in Denizli State Hospital and Ordu Obstetrics and Gynecology and Children's Hospital Pediatric Surgery clinics between January 2006 and December 2011 because of undescended testis were evaluated retrospectively in terms of the age at the time of surgery and the surgical methods performed. The patients were divided into two groups according to the age at the time of surgery as the first group who was operated at an age older than 2 years and the second group who was operated at the age of 0-2 years. After the dates of birth and operation were determined, the ages at the time of surgery were recorded as years in the first group and as months in the second group. The patients were operated by four different pediatric surgeons. In patients with non-palpable testis, laparoscopic 
orchiopexy was performed following scrotal ultrasonography. In patients in whom atrophic testis was found during operation, orchiectomy was performed after obtaining informed consent from the family who were given information about all the possibilities before operation. All patients were evaluated in terms of the location and dimensions of the testicle at the first day, first month and third month after surgery. Afterwards, the patients were called for regular follow-up visits with 6-month intervals. It was asked to the families of the both groups how the diagnosis was made and by whom the diagnosis was made and the families' levels of education were interrogated. The levels of education of the families in both groups were compared using Mann-Whitney $U$ test. In patients with delayed diagnosis, it was interrogated why the diagnosis delayed and if the child was examined by any physician before. In this way, the physicians' levels of attention and knowledge about this subject were investigated. This interrogation was made by face to face interviews with the parents of the patients who were operated in 2011 and who were randomly selected among the ones operated previously and came for follow-up vizit in 2011.

\section{Results}

494 testicles of 463 patients (250 right, 182 left and 31 bilateral) were included in the study. $59.4 \%$ of the patients
(275) were older than 2 years and these patients constituted the first group. $40.6 \%$ of the patients (188) were younger than 2 years and these patients constituted the second group (Table 1). Open orchiopexy and high ligation was performed in 393 testicles, laporoscopy assisted orchiopexy was performed in 12 non-palpable testicles and orchiectomy was performed in 9 patients because of atrophic testis. No statistically significant difference was found between the first and second groups in terms of the mean age and in terms of the number of patients who presented in years $(p>0.05)$.

A total of 180 relatives ( 90 from each group) were interviewed face to face. 76 of these patients were operated in 2011, while the remaining 104 patients were operated in previous years. The mean age was found to be $6.34 \pm 2.75$ years (3-13 years) in the first group and 15.97 \pm 6.01 (3-24 months) months in the second group. The majority of the patients in both groups lived in city centers (Table 1). No statistically significant difference was found between these patients who were operated in terms of living in city centers or in rural areas $(p>0.05)$.

When the levels of education of the families were evaluated, it was found that both the mothers and the fathers in the first and second groups were mostly primary school graduates and high-school and university graduates were found with a low rate (Table 2). A statistically significant difference was found between the education level of the family and early diagnosis $(p<0.05)$.

Table 1. General characteristics of all patients operated and included in the study

\begin{tabular}{|l|l|l|}
\hline & Group 1 (>2 years) & Group 2 (<2 years) \\
\hline The mean age of all patients & $\begin{array}{l}6.26 \pm 2.69 \text { years (3-13 years) } \\
(\mathrm{n}=275)\end{array}$ & $\begin{array}{l}1.83 \pm 5.62 \text { months (3-18 months) } \\
(\mathrm{n}=188)\end{array}$ \\
\hline $\begin{array}{l}\text { The mean age of the patients } \\
\text { included in the study }\end{array}$ & $\begin{array}{l}6.34 \pm 2.75 \text { years }(3-13 \text { years }) \\
(\mathrm{n}=90)\end{array}$ & $\begin{array}{l}15.97 \pm 6.01 \text { months }(6-24 \text { months) } \\
(\mathrm{n}=90)\end{array}$ \\
\hline Location of residence & $\begin{array}{l}\text { Center: } 56(62.2 \%) \\
\text { Town: } 19(21.1 \%) \\
\text { Village: } 15(16.6 \%)\end{array}$ & $\begin{array}{l}\text { Center }: 61(67.7 \%) \\
\text { Town:23 }(25.5 \%) \\
\text { Village:6 }(6.6 \%)\end{array}$ \\
\hline
\end{tabular}

Table 2. Education levels of the families of the patients who were operated

\begin{tabular}{|l|l|l|}
\hline & Group 1 (>2 years) & Group 2 (<2 years) \\
\hline Education level of the mother & Illiterate: 8 & Illiterate:1 \\
& Primary school: 60 & Primary school: 33 \\
& Secondary school: 6 & Secondary school: 17 \\
& High school: 14 & High school: 30 \\
& University: 2 & University: 9 \\
\hline \multirow{2}{*}{ Education level of the father } & Illiterate: 1 & Illiterate: 0 \\
& Primary schoold: 61 & Primary school: 37 \\
& Secondary school: 8 & Secondary school: 17 \\
& High school: 18 & High school: 26 \\
& University: 2 & University: 10 \\
\hline
\end{tabular}


Table 3. How undescended testis was recognized for the first time

\begin{tabular}{|c|c|c|}
\hline & Group 1 (>2 years) & Group 2 (<2 years) \\
\hline Recognized by the family and/or a relative & $26(28.8 \%)$ & $31(34.4 \%)$ \\
\hline Recognized during school screening & $20(22.2 \%)$ & - \\
\hline Recognized in the primary care setting & $25(27.7 \%)$ & $17(18.8 \%)$ \\
\hline Recognized by a pediatrician & $11(12.2 \%)$ & $41(45.5 \%)$ \\
\hline Pediatric surgeon or pediatric urologist & $8(8.8 \%)$ & $1(1.1 \%)$ \\
\hline
\end{tabular}

\section{Table 4. Reasons of delayed surgery and physicians who} performed previous examinations

\begin{tabular}{|l|c|}
\hline & $>2$ years \\
\hline Reasons for delayed surgery & \\
The family was not aware of the disease & $78(86.6 \%)$ \\
Family elders and/or neighbors told to wait & $7(7.7 \%)$ \\
They were concerned about anesthesia & $1(1.1 \%)$ \\
Another physician told to wait & $2(3.3 \%)$ \\
Absence of social security & $1(1.1 \%)$ \\
\hline Physicians who examined the child & \\
Never presented to any physician & $2(2.2 \%)$ \\
Only family physician & $23(25.5 \%)$ \\
Only pediatrician & $3(3.3 \%)$ \\
Both family physician and pediatrician & $60(66.6 \%)$ \\
Urologist & $2(2.2 \%)$ \\
\hline
\end{tabular}

In the first group, the presence of undescended testis was recognized most frequently by the family or a relative and by the family practicioner in the second order of frequency. In the second group, the presence of undescended testis was recognized most frequently by a pediatrician and by the family or a relative in the second order of frequency (Table 3 ). In interrogation of the families in cases with delayed diagnosis in the first group related to the cause of delayed diagnosis and the question if the child was examined by a physician before, the majority of the relatives stated that they were not aware of the disease and the child was examined by a pediatrician and family physician before for different reasons. Only two patients were not examined by any physician before (Table 4).

\section{Discussion}

The frequency of testicular cancer is gradually increasing in industrialized populations among young men (4). Although the reason for this increase is not very clear, it is known that cryptorchidism is a stong risk factor for testicular cancer and testicular cancer is parallel to the increase in the frequency of cryptorchidism (4,5). Many epidemilogical studies have reported that early orchiopexy decreases the risk of cancer in comparison to cases in which orchiopexy is not performed or performed in the late period $(4,5,6,7)$. When undescended testis is suspected in the newborn period, the male infant should be absolutely referred to a pediatric surgeon or pediatric urologist, if the testicle is still not in the scrotum at the age of 5-6 months. After a definite diagnosis of undescended testis is made, the child should be operated before the age of 18 months (probably between 6 and 18 months) (8).

Güven and Kogan (9) evaluated 552 patients who underwent orchiopexy with a mean operation age of 7.2 years and defined 177 patients (32\%) who were operated at the age of four and older as cases with delayed diagnosis. It has been shown that degenerative changes start in patients with undescended testis from the sixth month of life using electron microscope. Therefore, it would not be wrong to lower the age of delayed diagnosis to two years of age $(2,10,11)$. Accordingly, we divided our patients into two groups who were operated before and after two years of age in our study. Unfortunately, the rate of delayed diagnosis was found to be $59.4 \%$ in our study. The reason for this higher rate compared to the study of Güven may be the fact that we considered the patients who were operated between the ages of 2 and 4 as cases of delayed diagnosis.

Socioeconomic, geographical and anatomical factors are the most important factors which affect the time of consultation and treatment in patients with undescended testis (12). In a study performed in an urology clinic in 164 patients in Turkey, only 10\% of the patients were operated before the age of two, the mean age of operation was found to be $13 \pm 9$ years and the oldest age was reported to be 40 years (13). In an investigational study performed by Pettersson et al (14) in which the patient records between 1965 and 2000 in Sweden were examined retrospectively, the age of orchiopexy was investigated in 16983 male patients who had undergone orchiopexy before and only $4.2 \%$ (782 patients) of these patients were found to have been operated at the age of 0 2 years. In our study, this rate was found to be $40.6 \%$. The reason that this rate in our study was higher compared to other studies may be the fact that our clinics admitted only pediatric patients. Despite this fact this rate is not an acceptable one because even the mean age in the age group which is appropriate for surgery is more close to the upper limit considering the ideal target operation age is $6-18$ months $(1,2,3,15)$.

In the studies performed before, the most important reasons for this delay were reported to include low socioeconomic level 
of the family, delayed presentation to the physician and delayed referral of these patients from the primary care centers to pediatric surgery and pediatric urology centers. However, no detailed study has been conducted on this subject $(9,13,16,17)$. In our study, we tried to determine the level of education of the families and how the patients were referred and by whom they were referred to our outpatient clinic. We found that the education level of the families in the first group was statistically significantly lower for both the mother and the father compared to the second group. The fact that $86.6 \%$ of these families were not aware of the disease may be explained by the low education level. The fact that $97.7 \%$ of the patients in the first group had been examined by a physician before, but undescended testis was not recognized suggests that there are some faults at this point in our country. The most important reason for this may be the fact that physical examination is not performed as a whole, attention is only focused on the region of complaint and examination of the genital area is neglected. Therefore, it would be a more appropriate approach to emphazise delayed referral to specialist physicians instead of delayed presentation of the patients to a physician when noting the reasons of delayed surgery. However, this study was performed only in the parents of the patients and was a subjective observation in terms of physicians. We think that it would be more meaningful to conduct a study investigating the knowledge and attidute of physicians in the future. The reason that $65.5 \%$ of the patients in the second group were referred by physicians may be the fact that families with a higher education level stated that there was a genital problem in their children and directed physicians to examination of the genital area.

To prevent delayed surgery in undescended testis, suspicious cases can be referred to pediatric surgery and pediatric urology centers by contacting with primary care centers at which regular vacciantions and follow-up are performed from the newborn period, family physicians can be informed about the importance of the subject and nurses and midwifes can be teached simple testis palpation. In addition, genital area screening can be performed in male infants like hearing screening test which is applied successfully in our country considering that there is a pediatric surgeon in each province or enlightening information can be given to families by written and visual media. Another suggestion is to give more emphasis on testicular examination during education of medical students and residents of pediatric surgery.

Conclusively, it was found that the majority of the patients with undescended testis who all presented before adolescence and operated were older than two years and the mean age of the patients who were operated before the age of two was older than one year in this study which was conducted in pediatric surgery clinics in two different provinces belonging to two different regions in our country. These rates are not desirable for surgery of undescended testis. It is important to treat the patients at an early period in order to correct these rates and prevent infavourable affection of the patients.

\section{Conflict of interest: None declared.}

\section{References}

1. Tomiyama H, Sasaki Y, Huynh J, Yong E, Ting A, Hutson JM. Testicular descent, cryptorchidism and inguinal hernia: the Melbourne perspective. J Pediatr Urol 2005; 1(1): 11-25.

2. Hadziselimovic F, Herzog B. The importance of both an early orchidopexy and germ cell maturation for fertility. Lancet 2001; 358(9288): 1156-1157.

3. Capello SA, Giorgi LJ Jr, Kogan BA. Orchiopexy practice patterns in New York State from 1984 to 2002. J Urol 2006; 176(3): 1180-1183.

4. Walsh TJ, Dall'Era MA, Croughan MS, Carroll PR, Turek PJ. Prepubertal orchiopexy for cryptorchidism may be associated with lower risk of testicular cancer. J Urol 2007; 178(4): 1440-1446.

5. Herrinton LJ, Zhao W, Husson G. Management of cryptorchism and risk of testicular cancer. Am J Epidemiol 2003; 157(7): 602-605.

6. Strader $\mathrm{CH}$, Weiss NS, Daling JR, Karagas MR, McKnight B. Cryptorchism, orchiopexy, and the risk of testicular cancer. Am J Epidemiol 1988; 127(5): 1013-1018.

7. Maule M, Malavassi JL, Richiardi L. Age at puberty and risk of testicular cancer: a meta-analysis. Int J Androl 2012; 35(6): 828-834.

8. Thorup J, Haugen S, Kollin C, Lindahl S, Läckgren G, Nordenskjold A, Taskinen S. Surgical treatment of undescended testes. Acta Paediatr 2007; 96(5): 631-637.

9. Guven A, Kogan BA. Undescended testis in older boys: further evidence that ascending testes are common. J Pediatr Surg 2008; 43(9): 17001704.

10. Lee PA, Coughlin MT. Leydig cell function after cryptorchidism: evidence of the beneficial result of early surgery. J Urol 2002; 167(4): 1824-1827.

11. Ashley RA, Barthold JS, Kolon TF. Cryptorchidism: pathogenesis, diagnosis, treatment and prognosis. Urol Clin North Am 2010; 37(2): 183-193.

12. Bayne AP, Alonzo DG, Hsieh MH, Roth DR. Impact of anatomical and socioeconomic factors on timing of urological consultation for boys with cryptorchidism. J Urol 2011; 186(Suppl 4): 1601-1605.

13. Ceylan K, Yılmaz Y, Yıldız A, Kuş A, Gönülalan H. Kriptorşidizm: 164 olgunun; birlikte bulunan anomali, komplikasyon, tedavi modalitesi, hasta yaşı açısından irdelenmesi. Tıp Araştımaları Dergisi 2006; 4(3): 24-26.

14. Pettersson A, Richiardi L, Nordenskjold A, Kaijser M, Akre O. Age at surgery for undescended testis and risk of testicular cancer. $\mathrm{N}$ Engl $\mathrm{J}$ Med 2007; 356(18): 1835-1841.

15. Tekgül S, Riedmiller H, Gerharz E, Hoebeke P, Kocvara R, Nijman R, Radmayr Chr, Stein R. EAU guidelines on paediatric urology 2010: 8-10

16. Adayener C, Ates F, Soydan H, Turk L, Senkul T, Baykal K. The rates of external genital organ diseases in adolescent boys aged 13-15 years in Turkey. J Urol 2010; 36: 155-159.

17. Yılmaz Y, Odabaş Ö, Atan A, Demirtaş İ, Akman N, Aydın S. Awareness and the incidence of cryptorchidism in the Turkish population: an epidemiological study. Eastern Journal of Medicine 1997; 2: 26-28. 